\title{
KONVENSIONAL BED-BATH DAN PREPACKED DISPOSABLE BED-BATH DALAM PEMENUHAN KEBUTUHAN KEBERSIHAN DIRI PASIEN DI RUMAH SAKIT ADVENT BANDUNG
}

\author{
CONVENTIONAL BED-BATH AND PREPACKED DISPOSABLE BED-BATH FOR \\ FULFILLING PATIENTS' HYGIENIC NEED AT BANDUNG ADVENTIST HOSPITAL
}

\author{
Christmas Warastiko ${ }^{1}$, Sapti H. Widiyarti ${ }^{2}$ \\ Fakultas IImu Keperawatan, Universitas Advent Indonesia \\ E-Mail: christmaswarastiko@yahoo.com
}

\begin{abstract}
ABSTRAK
Pendahuluan: Setiap hari pasien butuh pemenuhan kebersihan diri mereka yaitu dimandikan oleh perawat karena kelemahan fisik dan kondisi sakit. Trend memandikan pasien saat ini sudah mengalami perubahan di berbagai rumah sakit yang beralih dari metode konvensional bed bath kepada disposable bed bath. Konvensional bed bath adalah metode memandikan pasien dengan cara tradisional yaitu menggunakan air dan sabun dalam menjaga kebersihan diri. Metode disposablebed bath adalah metode memandikan dengan menggunakan washcloth sekali pakai yang aman bagi kulit pasien. Tujuan: untuk membandingkan antara kenyamanan pasien yang menerima metode konvensional bed bath dan prepacked disposable bed bath dalam pemenuhan kebutuhan kebersihan diri di Rumah Sakit Advent Bandung. Metode: Penelitian ini adalah quasi exsperiment dengan desain penelitian crossover. Pengambilan sampel menggunakan teknik purposive sampling yang berjumlah 20 orang pasien yang dirawat di bangsal medical bedah Rumah Sakit Advent Bandung. Analisis yang digunakan dalam membandingkan kedua cara memandikan tersebut dianalisis menggunakan paired t-test. Hasil: Hasil penelitian menunjukan bahwa terdapat perbedaan yang signifikan dimana nilai $p$-value $\leq 0,05$. Meskipun kedua metode berada dalam rentang kategori baik namun didapati perbedaan yang bermakna dimana metode konvensional bed bath lebih membuat pasien merasa lebih nyaman saat setelah dimandikan. Diskusi: Hasil penelitian ini diharapkan dapat digunakan oleh bagian keperawatan dalam memberikan pelayanan pada pasien dalam pemenuhan kebutuhan personal hygiene yang membuat pasien merasa lebih nyaman.
\end{abstract}

Kata kunci: personal hygiene, konvensional bed bath, prepacked disposable bed bath, kenyamanan.

\begin{abstract}
Introduction: Trend of bathing patients currently undergoing changes in some hospitals such as Bandung Adventist Hospital and Bandar Lampung Adventist Hospital. The transition from how to bath with conventional methods of bed bath (water and soap) to the prepacked disposable bed bath use disposable washcloth give an extensive impact on the comfort of the patient. This study aims to comparing the comfort of patients receiving conventional methods of bed bath and prepacked disposable bed bath in fulfillment of self-hygiene needs in Bandung Adventist Hospital. Method: This research included in pre-experiment type with crossover research design. For retrieving the sample this research used purposive sampling that have the total of 20 patients that is hospitalized in South Wing III and West Wing III Bandung Adventist Hospital. A comparison these two variables using independent $t$-test formula. Result: result of the comparison that there are significant differences between the comfort of the patients who received conventional bed-bath and disposable bed-bath. These two methods are in the same level of convenient category, however there is still a valuable difference where the conventional method is better in making the patients feel more comfortable after having a bed bath. Discussion: Hopefully the result of this research is used by the nursing unit on giving more comfortable care to fulfill the patients' personal hygienic needs.
\end{abstract}

Key words: Personal hygiene, conventional bed bath, prepacked disposable bed bath, comfort.

\section{JURNAL SKOLASTIK KEPERAWATAN}

Vol, 3, No. 2

Juli - Desember 2017

ISSN: $2443-0935$ E-ISSN 2443 - 1699 


\section{PENDAHULUAN}

Setiap hari pasien butuh pemenuhan kebersihan diri mereka yaitu dimandikan oleh perawat karena kelemahan fisik dan kondisi sakit. (Horstmann, 2014). Kebersihan diri merupakan kondisi yang sangat penting diperhatikan dalam kehidupan sehari-hari karena mempengaruhi kesehatan dan psikis seseorang. Kebersihan diri seseorang merupakan bagian dari penampilan dan harga diri, sehingga seseorang yang mengalami keterbatasan dalam pemenuhan kebutuhan kebersihan diri dapat memengaruhi kesehatan orang tersebut (Tarwoto \& Wartonah, 2015). Menurut Virginia Henderson tentang konsep keperawatan dalam Lynn dan Oliver (2009) terdapat 14 jenis kebutuhan dasar manusia dan kebutuhan akan menjaga tubuh tetap bersih dan terawat serta melindungi integumen merupakan salah satu dari keempat belas kebutuhan dasar manusia tersebut.

Secara normal seseorang yang sehat mampu untuk memenuhi kebutuhan akan kebersihan diri dirinya sendiri. Orang yang sakit dapat memerlukan bantuan bantuan perawat, baik sebagian atau mandiri untuk melakukan pembersihan diri yang rutin. Perawat memilik tanggung jawab besar dalam menentukan kemampuan pasien untuk melakukan perawatan diri dan memberikan perawatan kebersihan sehubungan dengan kebutuhan pasien.

Perawatan kebersihan diri membuat klien menjadi bersih dan nyaman, disamping itu perawatan kebersihan diri membantu untuk mencegah infeksi, meningkatkan sirkulasi, mempertahankan integritas jaringan dan klien dapat menjadi lebih tenang dan rileks (Murwani, 2008).
Memandikan pasien di tempat tidur merupakan aktivitas membersihkan seluruh tubuh pasien yang terbaring di atas tempat tidur. Aktivitas ini umumnya dilakukan dengan air bersih dan sabun (Saputra, 2013). Seseorang yang tidak terjaga kebersihan dirinya sering mengalami gangguan rasa nyaman dan gangguan kesehatan kulit. Menurut penelitian yang dilakukan oleh Andriani (2016) di RSUD Ungaran Semarang, tentang gambaran persepsi pasien tentang pelaksanaan pemenuhan kebutuhan kebersihan diri pada 133 responden didapatkan bahwa sebagian besar 87 responden $(65,4 \%)$ mengaku bahwa pelaksanaan pemenuhan kebutuhan kebersihan diri tidak baik dalam pelaksanaannya, sehingga perawat perlu meningkatkan kualitas dalam pelaksanaan pemenuhan kebutuhan kebersihan diri untuk meningkatkan kepuasan, kenyamanan dan derajat kesehatan pasien.

Trend memandikan pasien saat ini sudah mengalami perubahan di beberapa rumah sakit seperti Rumah Sakit Advent Bandung maupun Rumah Sakit Advent Bandar Lampung. Di Rumah Sakit Advent Bandung sendiri praktik memandikan pasien menggunakan disposable washcloth sudah diterapkan selama beberapa tahun terakhir. Peralihan dari cara memandikan dengan metode konvensional bed bath (menggunakan air dan sabun) kepada prepacket disposable bed bath menggunakan disposable washcloth. Berdasarkan penelitian lain yang dilakukan oleh Horstmann (2014), tentang Elderly patients and nurses assessment of traditional bed bath compared to prepacked single units at Koge Hospitals terhadap 58 pasien yang menerima dua metode bed bath, 
(tradisional bed bath pada hari pertama dan disposable bed bath pada hari kedua) untuk mengukur durasi dan kualitas memandikan, biaya, kepuasan perawat dan pasien. Didapatkan hasil bahwa disposable washcloth lebih menghemat biaya, waktu memandikan lebih efisien, 24 pasien (47\%) lebih memilih menggunakan disposable bed bath, 11 pasien $(22 \%)$ lebih memilih tradisional bed bath, dan 16 pasien (22\%) merasa puas dengan kedua metode tersebut. Sebagian besar perawat lebih memilih menggunakan disposable washcloth.

\section{Personal Hygiene}

Kebersihan diri adalah upaya seseorang dalam memelihara kebersihan dan kesehatan dirinya untuk memperoleh kesejahteraan fisik dan psikologis. Pemenuhan kebersihan diri diperlukan untuk kenyamanan individu, keamanan, dan kesehatan. Kebersihan diri berasal dari bahasa Yunani yaitu personal artinya perorangan dan hygiene artinya sehat (Tarwoto \& Wartonah, 2015). Menurut Mubarak (2007) tujuan kebersihan diri adalah untuk memelihara kebersihan diri, menciptakan keindahan, serta meningkatkan derajat kesehatan individu sehingga dapat mencegah timbulnya penyakit pada diri sendiri maupun orang lain.

Menurut Hidayat (2012), tujuan umum kebersihan diri adalah untuk mempertahankan perawatan diri, baik secara sendiri maupun dengan menggunakan bantuan, dapat melatih hidup sehat/bersih dengan cara memperbaiki gambaran atau persepsi terhadap kesehatan dan kebersihan, serta menciptakan penampilan yang sesuai dengan kebutuhan kesehatan. Membuat rasa nyaman dan relaksasi dapat dilakukan untuk menghilangkan kelelahan serta mencegah infeksi, mencegah gangguan sirkulasi darah, dan mempertahankan integritas pada jaringan.

\section{Teori Comfort Kolcaba}

Menurut Katerine Kolcaba menyatakan kenyamanan adalah suatu konsep dasar keperawatan dengan praktek pelaksanaannya didasarkan pada prosedur dan kebutuhan dasar manusia. Kathrine Kolcaba adalah seorang perawat pendidik yang bergelar Phd, Dia seorang pertama kali menerapkan

Mid-Range Theory Comfort pada tahun 1991 dan dia melakukan analisis konsep literatur mengenai kenyamanan (Kolcaba, 2003).

Kolcaba menyatakan kenyamanan secara holistik merupakan pengalaman yang diperkuat secara transendensi yang terdiri dari empat konsep seperti kenyamanan fisik, kenyamanan psikospiritual, kenyamanan sosiokultural, dan kenyamanan lingkungan (Goodwin, Sener, \& Steiner, 2007). Kolcaba menjelaskan kenyaman fisik berfokus pada sensasi yang dirasakan oleh tubuh. Kenyamanan psikospiritual sebagai kenyamanan yang terkait dengan identitas, seksualitas, harga diri, dan hubungan spiritual. Kenyamanan sosio kultural sebagai kenyamanan yang dirasakan dari suatu hubungan interpersonal dan sosial dengan keluarga. Kenyamanan lingkungan sebagai pengalaman manusia terhadap lingkungan eksternal seperti suhu, cahaya, bau, warna, dan furnitur (Kolcaba, Tilton, \& Drouin, 2006).

Ketiga jenis kenyamanan dan empat konteks perawatan dalam teori kenyamanan Kolcaba dapat dimasukkan ke dalam model perawatan rumah sakit (Kolcaba, 
Tilton, \& Drouin, 2006). Selain itu, taksonomi kenyamanan dapat diterapkan untuk spesifik kasus pasien untuk menggambarkan berbagai kebutuhan kenyamanan pasien, sehingga diharapkan dapat meningkatkan pemenuhan kebutuhan kenyamanan pasien.

Menurut Kolcaba kenyamanan sebagai suatu elemen yang terdiri dari perasaan emosional dan fisik oleh individu yang mengalami (Apostolo \& Kolcaba, 2009). Hal ini berarti bahwa kenyamanan bersifat sangat subjektif, tidak jelas, dan beragam berdasarkan pemikiran atau pendapat individu masing-masing.

Kenyamanan dari suatu tindakan perawat mungkin dapat membuat nyaman seorang pasien tapi tidak demikian bagi pasien yang lain, dan seterusnya. Oleh karena itu, penting untuk mengidentifikasi kenyamanan dalam praktek keperawatan sebagai suatu tujuan dan seni dalam keperawatan begitu juga pada pasien yang dilakukan intervensi memandikan (Borzou, Anosheh, Mohammadi, \& Kazemnejad, 2014).

\section{Konvensional Bed-bath}

Menurut Horstmann (2104) konvensional atau tradisional bed bath adalah metode memandikan pasien dengan cara tradisional yaitu menggunakan air dan sabun dalam menjaga kebersihan diri. Menurut Kamus Besar Bahasa Indonesia (KBBI) memandikan pasien dengan cara tradisional adalah prosedur memandikan pasien dengan tujuan untuk menjaga dan memenuhi kebutuhan akan kebersihan diri dengan menggunakan air dan sabun. Menurut Saputra (2013) memandikan pasien di tempat tidur merupakkan aktivitas membersihkan seluruh tubuh pasien yang berbaring diatas tempat tidur. Memandikan pasien di tempat tidur untuk menjaga kebersihan kulit, mencegah bau badan, memberi rasa nyaman, dan merangsang peredaran darah. Memandikan pasien di tempat tidur dilakukan pada pasien yang tidak dapat mandi sendiri, misalnya karena keterbatasan gerak atau koma. Aktivitas ini umumnya dilakukan dengan menggunakan air bersih dan sabun.

\section{Prepacked disposable bed bath}

Selama beberapa dekade terakhir metode memandikan dengan disposable bed baths atau disposable washgloves/washcloths menjadi pilihan dalam pelaksanaan intervensi keperawatan dan sebagai alternatif dari memandikan metode konvensional.Metode disposablebed baths adalah metode memandikan dengan menggunakan washcloths sekali pakai.

Perusahaan Medline (2014) mengatakan bahwa disposable washcloths adalah kain lap sekali pakai yang lembut dan sangat kuat saat basah, dan higienis karena mengandung air dan sabun pembersih, pelembab dan antiseptik yang dapat membunuh bakteri dan jamur. Disposable bath sendiri sudah di kembangkan sejak tahun 1994 yang pada saat itu disebut bag bath.

Dimana delapan washcloths dikumpulkan dalam satu kantung yang mana sebelumnya telah diberi detergent solution dan kemudian di panaskan dalam oven microwave yang tujuannya adalah untuk mensterilkan bag bath itu sendiri. Sebelum digunakan terhada pasien, bag bath harus dibasahi terlebih 
dahulu Skewes (1994) dalam Horstmann (2014).

\section{BAHAN DAN METODE}

Penelitian ini termasuk kedalam jenis penelitian quasi experiment dengan menggunakan crossover design.

Populasi dalam penelitian ini adalah pasien yang dirawat di ruang Southwing III dan Westwing III Rumah Sakit Advent Bandung.

Sampel dalam penelitian ini adalah 20 orang pasien yang masing-masing 10 orang pasien dari Southwing III dan 10 orang pasien dari Westwing III menggunakan teknik purposive sampling. Penelitian dilakukan dengan cara memberikan dua tindakan pemenuhan kebutuhan kebersihan diri kepada setiap pasien.

Hari pertama pasien menerima metode konvensional lalu mengisi kuesioner tentang kenyamanan yang dirasakan dan hari kedua menerima metode prepacked disposable bed bath dan mengisi kuesioner kenyamanan.

Kuesioner yang digunakan berjumlah enam item penilaian kenyaman yang dirasakan pasien setelah menerima tindakan yang telah diuji validasi dengan empat orang ahli. Pengukuran menggunakan skala likert dengan metode scoring. Setiap pilihan jawaban diberi skor, yaitu: 1= sangat tidak nyaman, $2=$ tidak nyaman, $3=$ cukup nyaman, $4=$ nyaman, $5=$ sangat nyaman . Pengumpulan data dilakukan dengan cara peneliti memberikan dua tindakan personal hygiene kepada pasien di hari yang berbeda. Pasien mengisi kuesioner tentang penilaian kenyamanan setelah menerima setiap tindakan pemenuhan kebersihan diri. Penelitian dan pengumpulan data dilakukan pada $12-$
28 Maret 2017 di ruang perawatan Southwing III dan Westwing III Rumah Sakit Advent Bandung yang kemudian di interprestasikan sesuai dengan tabel berikut:

Tabel 1. di bawah ini menggambarkan kenyamanan pasien pasien yang menerima tindakan pemenuhan kebutuhan personal hygiene dengan metode konvensional bed bath.

Tabel 1. Rentang kategori kenyamanan pasien

\begin{tabular}{llc}
\hline Nilai & Kategari & Interprestasi \\
\hline 1.00-1.79 & Sangat tidak & Sangat \\
1.80-2.59 & Tidak baik nyaman & \\
$2.60-3.39$ & Tidak baik & Tidak nyaman \\
$3.40-4.19$ & Cukup baik & Cukup nyaman \\
$4.20-5.00$ & Baik & Nyaman \\
& \multicolumn{2}{c}{ Sangat baik Sangat nyaman } \\
\hline
\end{tabular}

\section{HASIL}

Secara demografik subjek penelitian memiliki pendidikan SD sebanyak 3 orang (15\%), SMP sebanyak 3 orang (15\%), SMA sebanyak 8 orang $(40 \%)$, D3 sebanyak 1 orang $(5 \%)$, dan S1 sebanyak 5 orang (25\%). Profil usia sampel menunjukan bahwa usia 20-28 tahun sebanyak 5 orang (25\%), usia 2937 sebanyak 5orang (25\%), usia 38-46 sebanyak 7 orang (35\%), dan usia 47-55 sebanyak 3 orang (15\%).

Tabel 2. dibawah ini menggambarkan kenyamanan pasien yang menerima tindakan pemenuhan kebutuhan personal hygiene dengan metode disposable bed bath.

Tabel 2. Nilai Rata-rata kenyamanan Pasien dengan Konvensional Bedbath

Nilai rata-rata Kategori
kenyaman an
pasien

B,95 Baik Nyaman


Dari tabel diatas, hasil analisis data menunjukan bahwa nilai rata-rata kenyamanan pasien adalah 3,95 yang berada dalam kategori baik dengan interprestasi nyaman.

Tabel 3. Nilai Rata-rata Kenyamanan Pasien dengan Disposable Bed-bath

$\begin{array}{lcc}\text { Nilai rata-rata } & \text { Kateg } & \text { Interprest asi } \\ \text { kenyaman an } & \text { ori } & \\ \text { pasien } & & \end{array}$

\begin{tabular}{lll}
\hline 3,49 & Baik & Nyaman \\
\hline
\end{tabular}

Dari tabel di atas, hasil analisis data menunjukan bahwa nilai rata-rata kenyamanan pasien adalah 3,49 yang berada dalam kategori baik dengan interprestasi nyaman.

Tabel 4 berikut ini menunjukan hasil analisis uji perbedaan dari paired t-test menggunakan spss versi 20 .

Tabel 4. Independent t-test

\begin{tabular}{llll}
\hline & t & Df & Sig. (Ztailed) \\
& & & \\
\hline $\begin{array}{l}\text { Konvensional } \\
\text { disposable }\end{array}$ & 4,66 & 19 & ,0 \\
\hline
\end{tabular}

Berdasarkan tabel di atas, hasil analisis data menunjukan bahwa nilai t-hitung 4,660 dan nilai $p$-value 0,001 .

\section{PEMBAHASAN}

Untuk identifikasi maslah pertama dan kedua "Bagaimanakah kenyamanan pasien yang menerima tindakan pemenuhan kebutuhan kebersihan diri dengan metode konvensional bed bath dan disposable bed-bath di Rumah Sakit Advent Bandung?" dijawab dengan menentukan nilai rata-rata dari kenyamanan responden setelah itu diinterprestasikan sesuai dengan rentang kategori kenyamanan pasien.
Tabel 5. Rentang katergori kenyaman pasien

\begin{tabular}{lll}
\hline Nilai & Kategari & Interpretasi \\
\hline I.DO - 1.79 & Sangat tidak baik & $\begin{array}{l}\text { Sangat tidak } \\
\text { nyaman }\end{array}$ \\
1.80 - 2.59 & Tidak baik & Tidak nyaman \\
$2.60-3.39$ & Cukup baik & Cukup nyaman \\
$3.40-4.19$ & Baik & Nyaman \\
$4.20-5.90$ & Sangat baik & Sangat nyaman \\
\hline
\end{tabular}

Berdasarkan perhitungan nilai rata-rata kenyamanan pasien yang menerima metode konvensional bedbath berada dalam kategori baik dan interprestasi nyaman dengan nilai rata-rata 3,95 . Hal ini dipengaruhi oleh pola kebiasaan yang dilakukan pasien selama dirumah, dimana mereka biasa mandi menggunakan air dan sabun. Beberapa pasien juga mengatakan bahwa badan terasa lebih segar apabila dimandikan dengan air dan sabun. Hal ini didukung oleh hasil penelitian yang dilakukan oleh Sheppard \& Brenner (2000) yang menyatakan bahwa penggunaan metode konvensional bed bath lebih efektif terhadap hidrasi kulit dibandinggkan dengan disposable bed bath terhadap hidrasi kulit dengan nilai $P$-value $\leq 0,00$. Berdasarkan perhitungan nilai rata-rata kenyamanan pasien yang menerima metode disposable bedbath berada dalam kategori baik dan interprestasi nyaman dengan nilai rata-rata 3,4917. Memandikan pasien dengan metode disposable bed bath memberikan rasa nyaman kepada pasien. Hal ini didukung oleh penelitian yang dilakukan oleh Horstmann (2014) tentang Elderly patients and nurse's assessment of traditional bed bath compared to prepacked single units at Koge Hospitals terhadap 58 pasien yang menerima dua metode bed bath, (tradisional bed bath dan disposable bed bath) dimana sebagian besar pasien ( 24 pasien / 47\%) merasa puas dengan metode disposable 
bed bath yang mereka terima dalam menjaga kebersihan diri.

Untuk menjawab identifikasi masalah ketiga, yaitu: "Adakah perbedaan yang signifikan antara kenyamanan pasien yang menerima tindakan pemenuhan kebutuhan kebersihan diri dengan metode konvensional bed-bath dan prepacked disposable bed-bath di Rumah Sakit Advent Bandung?" maka dilakukan uji hipotesis menggunakan uji paired t-test. Analisis dari identifikasi masalah ketiga menunjukan bahwa ada perbedaan yang signifikan dengan nilai $P$-value $\leq 0,05)$ antara kenyamanan pasien yang menerima tindakan pemenuhan kebutuhan kebersihan diri dengan metode konvensional bed-bath dan prepacked disposable bed-bath di Rumah Sakit Advent Bandung. Analisis data ini memperlihatkan bahwa konvensional bed bath menggunakan air dan sabun memberikan kenyamanan yang lebih pada pasien.

Metode konvensional bed bath lebih disukai oleh pasien dan pasien merasa lebih nyaman karena pola kebiasaan yang biasa mereka lakukan untuk menjaga kebersihan diri dirumah yaitu dengan mandi menggunakan air dan sabun dan mereka merasa lebih segar setelah disiram dengan air. Hal ini sesuai dengan apa yang sudah dijelaskan oleh Kolcaba bahwa kenyaman fisik berfokus pada sensasi yang dirasakan oleh tubuh (Kolcaba,Tilton, \& Drouin, 2006).

\section{KESIMPULAN}

Kenyamanan pasien yang menerima metode konvensioanl bed bath termasuk dalam rentang kategori baik dan interprestsi nyaman dengan nilai ratarata 3,95, dan kenyamanan pasien yang menerima metode disposable bed bath termasuk dalam rentang kategori baik dengan nilai rata-rata 3,49 . Hasil uji perbedaan dengan paired t-test menunjukan bahwa terdapat perbedaan yang bermakna (signifikan) dalam kenyamanan pasien yang menerima metode konvensional bed bath dan disposable bed bath dalam pemenuhan kebutuhan kebersihan diri di ruang rawat inap West Wing III dan South Wing III Ruma Sakit Advent Bandung dengan nilai $p$-value $(0,000)<$ nilai $\alpha(0,05)$.

\section{DAFTAR PUSTAKA}

Andriani, Devi. (2016). Gambaran persepsi pasien tentang pelaksanaan pemenuhan kebutuhan personal hygiene oleh perawat di RSUD Ungaran. Semarang. Universitas Diponegoro. (Skripsi). [Online]. Available at http://eprints.undip.ac.id/49594/ [14 September 2016].

Apostolo \& Kolcaba, K. (2009). The effects of guided imagery on comfort depresion, anxiety, and stress of psychiatric inpatients with depressive Disorders. [Online]. Available at http:www.sciencerdirect.com [14 September 2016].

Arita. murwani. (2008). Pengantar konsep dasar keperawatan,Edisi 1, Fitramaya: Yogyakarta

Basford Lynn \& Oliver Slevin. (2009). Teori dan Praktik Keperawatan Pendekatan Integral Asuhan Pasien; Alih Bahasa, Agung Waluyo. Editor edisi bahasa Indonesia Monica Ester Skp.Jakarta: EGC.

Borzou, S.B. Anosheh, M. 
Mohammadi, E. Kazemnejad, A (2014). Patients' Perception of Comfort Facilitators During Hemodialysis Procedure: A Qualitative Study. Iranian Red Crescent Medical Journal, 16 (7). [Online]. Available at https://www.ncbi.nlm.nih.gov/p m c/articles/ PMC4166106/ [2 April 2016].

Goodwin, M. Sener, I. \& Steiner, S.H. (2007). A Novel Theory for Nursing Education. Holistic Comfort. Sage Journals, 25 (4), 278-85 [Online]. Available at https://www.ncbi.nlm.nih.gov/pu bmed/18029969 [2 April 2016].

Hidayat, A. A. (2012). Riset

Keperawatan dan Teknik

Penulisan Ilmiah. Salemba Medika: Edisi 2.

Hortstmann L, Hemmingsen LE, Hørdam B (2014). Elderly patients' and nurses' assessment of traditional bed bath compared to prepacked single units randomised controlled trial. Scandinavian Journal of Caring Sciences. 29 (2). 347-352

Kolcaba, Katherine. (2003). Comfort theory and practice: a vision for Holistic Health Care and Research. New York: Springer Publishing Company.

Kolcaba, K., Tilton, C., \& Drouin, C. (2006) comfort theory a unifying framework to enhance the practice environment. The journal og Nursing Administration, 36 (11) 538-544.
Pengantar Proses Belajar Mangajar dalam Pendidikan. Yogyakarta: Graha Ilmu.

Saputra, Lyndon. (2013). Kebutuhan Dasar Manusia. Tangerang Selatan: Binarupa Aksara.

Sheppard, C.M. \& Brenner, P.S (2000). The effects of bathing and skin care practices on skin quality and satisfaction with an innovative product. Journal Gerontological Nursing. 26 (10). 36-45. [Online]. Available at https://www.ncbi.nlm.nih.gov/pu bmed /11883497 [2 April 2016].

Tarwoto \& Wartonah. (2015). Kebutuhan Dasar Manusia dan Proses Keperawatan Edisi ketiga. Jakarta: Salemba Medika.

Mubarak, Wahit Iqbal, dkk. (2007). Promosi Kesehatan Sebuah 